This article has been published in Medical Humanities following peer review and can also be viewed on the journal's website at https://doi.org/10.1136/medhum-2015-010862

Full citation:

Acai, A., McQueen, S. A., Fahim, C., Wagner, N., McKinnon, V., Boston, J., . . Sonnadara, R. R. (2016). 'It's not the form; it's the process': A phenomenological study on the use of creative professional development workshops to improve teamwork and communication skills. Medical Humanities, 42(3), 173-180. https://doi.org/10.1136/medhum-2015$\underline{010862}$ 


\title{
"It's Not the Form; It's the Process": A Phenomenological Study on the Use of Creative Professional Development Workshops to Improve Teamwork and Communication Skills
}

\begin{abstract}
Introduction: Past research has demonstrated the positive effects of visual and performing arts on health professionals' observational acuity and associated diagnostic skills, well-being, and professional identity. However, to date, the use of arts for the development of non-technical skills, such as teamwork and communication has not been studied thoroughly.

Methods: In partnership with a community print and media arts organization, Centre[3], we utilized a phenomenological approach to explore front-line mental health and social service workers' experiences with a creative professional development workshop based on the visual and performing arts. Through pre- and post-workshop interviews with participants and postworkshop interviews with their managers, we sought to examine how participants' perceptions of the workshop compared to their pre-workshop expectations, specific impacts of the workshop with respect to participants' teamwork and communication skills, and changes in their perceptions regarding the use of the arts in professional development.

Results: Our workshops were successful in enhancing teamwork skills among participants and showed promise in the development of communication skills, though observable changes in workplace communication could not be confirmed. The workshop facilitated teamwork and collegiality between colleagues, creating a more enjoyable and accepting work environment. The workshops also helped participants identify the strengths and weaknesses of their communication skills, made them more comfortable with different communication styles, and provided them with strategies to enhance their communication skills.
\end{abstract}


Conclusions: Participation in the arts can be beneficial for the development of interpersonal skills such as teamwork and communication among health professionals. 


\section{Introduction}

Education programs for health professionals are increasingly incorporating learning opportunities involving engagement with the visual and performing arts into their curricula. Some of these activities, such as guided museum tours, involve students as observers of art, whereas others, such as collage-making or the development of a musical production, involve students as participants in the creation of art [1]. Past research has demonstrated that participation in the arts can have positive effects on health professionals' observational acuity and associated diagnostic skills [2-5], well-being [6,7], and professional identity [6].

While the role of the arts in technical skill development (i.e., observational and interpretive skills) has been reported in the literature, less work has been done on the use of arts in the development of interpersonal skills. Nonetheless, a handful of studies have explored the use of the visual and performing arts to enhance skills such as teamwork and communication among health professionals. For example, Sheingold et al. [8] found, through a qualitative analysis of students' artwork and reflections, that engaging nursing students in a drawing exercise helped participants understand subversive team issues and identify root causes of dysfunction in their immediate work environments. In addition, a study by Klugman et al. [9] demonstrated an improvement in medical and nursing students' attitudes towards communication following a series of guided reflections on art. Freeform student responses revealed that many students gained a better appreciation for multiple perspectives, enhanced their listening skills, and learned about teamwork and group processes. Participating in musical theatre has also demonstrated benefits by developing a sense of community among participants [10], while roleplaying can help participants show empathy towards others, which is an important attribute for health professionals [11]. In addition, engagement in music and the dramatic arts has been shown 
to benefit teams who routinely work under high-stress conditions by bringing team members closer together, facilitating more open dialogue, and encouraging team members to support one another through challenging circumstances $[12,13]$.

Although these studies provide preliminary evidence that the arts may be beneficial in promoting the development of teamwork and communication skills, a number of shortcomings exist with regard to their methodologies. First, many of the studies rely solely upon subjective, self-reported measures. Such measures provide insight into participants' attitudes toward participation in the arts, but make it difficult to draw definitive conclusions regarding the effectiveness of these activities in eliciting actual behavioural change [1]. Second, even in studies where participants are directly asked to report on their skill development, specific examples of workplace changes are not mentioned. This makes it challenging to gauge the accuracy of participants' reports or the extent of the changes that have taken place. In light of evidence suggesting that human self-assessment ability is relatively poor [14], it is necessary to rely on measures beyond self-assessment alone when evaluating the efficacy of creative professional development opportunities.

Given these considerations, the aim of our current study was to add to the limited body of research on the use of the creative arts to enhance interpersonal skills among health professionals. A phenomenological approach was used to answer the research question: "Can a creative professional development workshop facilitate the development of interpersonal (teamwork and communication) skills among teams of health professionals?" Our specific objectives were to: 1) thoroughly explore participants' workshop experiences and the impact of the workshop on workplace teamwork and communication skills, and 2) evaluate changes in participants' attitudes toward the use of the arts for professional development as a result of the 
workshop, as reported by both participants and their managers. While we were interested in assessing the role of the creative arts in interpersonal skill development, we chose to specifically focus on teamwork and communication skills in order to be able to more clearly identify the outcomes of the workshop. These skills were selected because of their importance in professional accreditation body guidelines internationally, including the Canadian CanMEDS roles, which include "communicator" and "collaborator" as two of the seven key competencies for medical practitioners [15-17].

\section{Methods}

This was a collaborative project between a community-based, artist-run print and media arts organization, Centre[3], and a multi-disciplinary research team at McMaster University, both located in Hamilton, Ontario, Canada. A professional actor and a practicing artist, both of whom are arts educators, were responsible for developing and facilitating a series of creative professional workshops. The research team from McMaster was responsible for conducting a qualitative study examining the efficacy of the workshops. This included scheduling and conducting interviews, transcribing, analyzing interview data, and preparing written documents. The research team at McMaster also prepared and submitted the ethics protocol for this study, which was approved by the McMaster University Research Ethics Board (MREB 2015-037).

\section{Workshops}

The workshops followed a similar format on each occasion. The morning consisted of various interactive teambuilding games and activities rooted in the dramatic arts, while the afternoon was a creative printmaking session that resulted in the co-creation of a mural. The goal of the workshops was to foster teamwork and communication skills among colleagues in a hands-on, collaborative manner. Therefore, activities were supplemented with debrief sessions, 
which encouraged participants to reflect on each activity and how what they have learned might apply in a professional context.

The social therapeutics model, with origins in the work of Marx and Vygotsky, served as the theoretical foundation for the workshops [18]. Social therapeutics posits that individuals are creators of their culture and are enact performances on a regular basis throughout their lives, which is a form of learning and development. Although the method was initially a form of radical psychotherapy, it has since advanced into a practical human improvement philosophy with a wide application over a variety of contexts and cultures. Thus, rather than focusing on individualized pathologies and problem solving, individuals instead engage in social growth and collective creativity. Much of this is done through play and performance, which allows for human and community development to take place in an organic way [18].

\section{Workshop participants}

Workshop participants included front-line mental health and social services staff from the Youth Services department at a community organization in Hamilton, Ontario, Canada that provides programs and services to vulnerable members of the community. The front-line staff worked as four separate teams at four primary locations and specialized in supporting and treating youth struggling with a variety of social, emotional, behavioural, mental health and addictions issues. Front-line staff at these locations held a variety of roles, including youth support worker, senior/lead youth support worker, early childhood educator, recreationist, mental

health clinician, youth addictions worker, early intervention case manager, intensive community case manager, and youth homeless prevention case manager. One response was also received from a superintendent. While this was not considered a direct front-line role, the participant 
provided useful insight and their responses were therefore retained as a complementary perspective for the study.

\section{Interviews}

Managers from the community organization provided the study team with a list of potential workshop participants from each primary location. Each participant was contacted by the research team via email and provided with both information about the study and a consent form. Participants were asked to provide consent to participate in a pre-workshop interview (conducted one to two weeks prior to the workshop), a post-workshop interview (conducted up to three weeks after the workshop), or both. Interviews were semi-structured, conducted by telephone, and lasted approximately 15 minutes each. All interviews were audio-recorded and transcribed verbatim by a member of the research team.

\section{Data analysis}

A phenomenological approach was used in order to thoroughly assess participants' experiences with the workshop and its specific impacts on interpersonal skills development. The phenomenological method is an inductive, descriptive research method with the purpose of fully understanding a particular phenomenon as it truly appears or is experienced, as well as the effect that the phenomenon has on the lived experience or behaviour of participants [19]. This method, therefore, calls for researchers approach their work without any preconceived notions and without seeking to validate any preselected theoretical framework.

Our approach to phenomenological analysis was most consistent with the approach outlined by Giorgi $[20,21]$. To carry out our analysis, interviews were systematically divided among the five researchers. Coding was completed in two stages using NVivo 10 for Mac (QSR International). First, open coding was used to determine distinct concepts and categories in the 
data. Second, axial coding was used to group text from each interview into one or more of the open codes. The research team coded three transcripts together to ensure consistency in coding. Once coding was complete, one of the researchers (who had read each interview in its entirety and was familiar with all of the data) integrated and synthesized insights into a descriptive narrative, which is summarized in this article.

\section{Results}

A total of four creative professional development workshops were delivered by Centre[3] between April and May 2015. Forty-eight participants consented to both pre- and post-workshop interviews. However, four withdrew from the study prior to the pre-workshop interview and eight did not respond to the pre-workshop request. Therefore, a total of 36 pre-workshop interviews were conducted. Following the pre-workshop interviews, one participant withdrew from the study, two did not attend the workshop, and one did not respond to the post-workshop interview request. As a result, a total of 30 post-workshop interviews were conducted. In addition, four managers (one per primary location) were interviewed one month post-workshop in order to provide a second perspective on the impact of the workshops on participants' professional development.

\section{Pre-workshop interviews}

The following elements were explored in the pre-workshop interviews: pre-workshop perceptions of teamwork and communication, attitudes towards and expectations of the workshop, and perceptions of the use of the arts for professional development (see Supplementary Table 1 for a summary of findings from the pre-workshop interviews). 
Pre-workshop perceptions of teamwork and communication

We were particularly interested in participants' perceptions of teamwork and communication in their immediate work environment prior to participation in the workshop. Participants from two of the four primary locations spoke very positively about teamwork and communication in their immediate work environment.

I think the team is actually pretty amazing. It's probably one of the best teams right now that I work with. (Participant 4D)

On the other hand, participants from the other two primary locations were divided in their perceptions of teamwork and communication. This was attributed to several factors, including a work environment that had recently undergone a considerable number of staffing changes. This was significant, as team size and cohesion were attributed to a positive team culture.

Recently we've had a lot of people come onto staff and that's something that's going to take time. We're going to have to learn to work with each other, learn to trust each other... that kind of thing. It just takes time. (Participant 6B)

Other participants perceived challenges in regards to the top-down management structure in the workplace. In particular, this structure was demonstrated to affect employee morale and impact communication between colleagues.

We have a top-down hierarchy where the people at the top have all of the information and the people at the bottom and the front-line staff don't always have the information they need to make the decisions that they're faced with. I think there's a gap there. (Participant 4B)

The same divide was identified between full-time staff, who worked during the week, and part-time staff, who worked on weekends. Because the two groups did not often interact, information sharing and communication between full-time and part-time staff was commonly perceived as a challenge. However, effective communication was often identified as a challenge even among workers who otherwise had very positive perceptions 
of their work environment. Barriers to effective communication included time constraints and the busy nature of the social work environment, as well as the volume of information that had to be handled and passed on.

The nature of the workplace is so busy and the needs of our clients are so complex and consistent that it's hard to carve out that time to connect with staff. (Participant 4B)

Many of the barriers to teamwork and communication that were repeatedly identified by participants from all four primary locations appeared to stem from systemic problems, such as the challenges and demands of the social work environment. Teamwork and communication were both identified as areas where there was an opportunity for improvement, or at the very least continued development, to occur.

Pre-workshop attitudes and expectations

At the time of the pre-workshop interviews, most of the participants had a positive attitude about the upcoming workshop and were looking forward to it. They seemed especially enthusiastic about the opportunity to get to know their colleagues outside of their work environment, indicating that this was not a frequent occurrence, given the nature of their work.

It gives us an opportunity to be together as a team because here we don't have shift partners, so it's very pass and go with communicating with your team. So, it's nice to have a day when everyone is together. (Participant 3A)

Aside from being an opportunity to be together as a team and to develop a closer bond, participants also saw the workshop as an opportunity for particular aspects of teamwork and communication to be developed or enhanced. Specific examples included building a better sense of trust within the team and learning to communicate concerns and address interpersonal conflict. In addition, participants were looking forward to the opportunity to be creative, which was perceived as a unique aspect of the workshop that most participants had not experienced before 
as part of professional development.

You don't often see creative professional development opportunities unless you're in the field. It's the first time I'd be doing this with this particular organization, so I'm excited. I'm a very creative person. (Participant 5A)

While none of the participants had negative attitudes about the workshop, some participants seemed to have neutral attitudes. Some staff indicated that they were not sure what to expect from the workshops or that they had no real expectations as they had not been told much about the workshops and had not experienced anything similar before. However, these participants appeared to be going into the workshop with an open mind. Pre-workshop thoughts on using the arts for professional development

A unique aspect of Centre[3]'s professional development workshops is the use of shared participation in the arts to build teamwork and communication skills. Therefore, we were interested in exploring participants' perceptions of using the arts for professional development both before and after their workshop experience.

Several participants already had a very positive view of the arts before participating in the workshop. A few of these participants had engaged in similar creative professional development workshops in the past, although most had not. However, most of the participants had gained experience with the arts in other ways, such as through hobbies or the design of therapeutic activities for the youth with whom they worked.

Of those who had positive conceptions of using the arts for professional development, there were several reasons why people believed that art could be useful in this context. The most prevalent finding was that art was seen as a way of expression and communication that is accessible to all people. Participants felt that because there is no right or wrong answer when it comes to the arts, everyone should be able to participate in the process of art making and might 
even feel more comfortable expressing themselves in this way.

It's one of the easiest ways to actually communicate with somebody...It's one of the easiest ways to get...messages across to people. (Participant 10B)

One participant also suggested that since many art-based activities are hands-on, participants might be more engaged in the professional development opportunity and would therefore take more away from the experience.

I think people learn the best through doing things and experiencing stuff, so... I think it'll be a good medium to learn things and retain the information better. (Participant 9C)

Another participant discussed the benefits of arts in terms of self-discovery and selfawareness, something that she ultimately felt could benefit her colleagues' development in the same way that it had benefited her in her prior experiences with art.

Nonetheless, not all participants were as optimistic about the use of the arts for professional development. Some indicated that they did not conceptualize art as something that could be used in the context of professional development. Others felt that the workshop might not be useful for those individuals who did not have an innate artistic ability.

What happens if somebody is not artistic? Not everyone is able to get their message across though art. If they're not, I'm not sure how this works. (Participant 4A)

In summary, participants' pre-workshop conceptions of using the arts for professional development were somewhat mixed, with some participants seeing great value in the use of art and others finding the idea more elusive.

\section{Post-workshop interviews}

The following elements were explored in the post-workshop interviews: overall perceptions, specific impacts of the workshop on teamwork and communication, and perceptions 
of the use of the arts for professional development (see Supplementary Table 2 for a summary of findings from the post-workshop interviews).

Overall perceptions

Participants had very positive perceptions of the creative professional development workshops. Nearly all participants were enthusiastic about the workshops, indicating that it was an enjoyable way to have spent a day with their colleagues. For a number of participants, the workshop appeared to have exceeded their expectations. Participants especially enjoyed that the workshops were hands-on and interactive; both elements were helpful in engaging participants.

Everybody was thinking beforehand, "Are you going to this? And what is this all about? And how are we going to improve communication through art?" But it was totally, totally different ... I don't know how they could describe what we went through that day. Walking around blind-eyed and drawing pictures, you had to be there. There's nobody that said they didn't enjoy it. (Participant 1C)

Specific impacts: teamwork

Most participants' comments supported the fact that the workshops had had a positive impact on team development. The most salient finding regarding teamwork was that the workshops gave staff the opportunity to spend time together-something that, as previously mentioned, does not occur often in their particular work environment. This helped staff bond and get to know each other better. Many participants noted the benefit of having the workshops outside of the work environment, allowing participants to see a different side of their colleagues.

We weren't solving a crisis; we weren't trying to modify people's behaviour. We were just being a team together. I think that was really, really helpful. I think it made a huge difference. (Participant 9B)

As a result, several participants indicated that they felt closer with each other when they returned to work; in particular, they were more relaxed around one another and were more apt to joke around and interact with their colleagues in a less formal way. 
I've seen the changes at work, absolutely...we joke around with each other...it's not so uptight. Now that we've seen that silly side of everybody, we've felt more comfortable. (Participant 5B)

Participants also described how another tangible impact was that staff members now seemed more accepting of each other's mistakes in the workplace. Even when back at work, they found themselves drawing upon a particular workshop activities (“I made a mistake!") that helped them recognize the humanity in making an error and that it is often more beneficial to celebrate mistakes rather than to chastise them.

[The workshop] made us discover that now when we make a mistake, instead of being like, "Oh, it's a mistake," we celebrate it, because yes, it's a mistake, but we can learn from it. (Participant 2C)

In the few cases where staff did not report having seen any change in teamwork as a result of the workshop, this was generally attributed to the fact that their team was already very tight-knit prior to the workshop and did not need much development in this regard.

We were a very good team to begin with, so I don't know if we needed to work on anything in that area, but we're not any worse! (Participant 6D)

Therefore, the majority of the professional development that occurred in the context of teamwork seemed to center on developing a better sense of team cohesion and getting colleagues to get to know each other so that they could be more comfortable with and accepting of one another. This was particularly relevant in staff members' work environments, given that they did not often get the chance to interact due to a divide between full-time and part-time staff, the demands of their work environment, and in some cases, because of recent staff turnover. Specific impacts: communication

Similar to teamwork, participants' responses suggested that the workshop had led to some development in terms of participants' communication skills. In particular, participants indicated 
that the workshop made them more aware of their existing strengths and weaknesses in communication and helped them identify team issues that needed to be rectified.

It was evident throughout the day where we excelled and where we really, really don't excel ... I think it allowed for conversation that would ... otherwise not happen. (Participant 6C)

The workshop also allowed participants to become more exposed to their colleagues' unique communication styles and to become more comfortable communicating with them in a professional context.

It made us recognize other people's ways of relating in a team and then how to... communicate with them during those activities. (Participant $3 \mathrm{~A}$ )

Finally, the workshop provided participants with a range of effective communication strategies that they could apply in both their personal and professional lives. Many participants cited an activity where they learned about the use of "yes, and" versus "yes, but" as being particularly helpful in this regard.

It gave us different ways to communicate with others without it sounding negative so that when we are communicating, we can talk in a positive way and build on ideas, rather than just cutting off ideas. We learned how to build on ideas ... Somebody would come up with an idea, then I had to answer "yes but" and then continue on. And then we changed it to "yes, and" and it made so much difference in the communication of ideas. (Participant 4A)

Participants also suggested that while the workshop had made them more aware about their strengths and weaknesses in communicating as a team and strategies that they could use, it would take more time for these newfound skills to be put into practice and for their effects to be seen.

I wouldn't say improvement yet, because it does take time for all of us... I haven't noticed anything change yet, but now we're more aware. (Participant 3D) 
Some participants expressed concern that while a one-off workshop may have created a greater awareness around the importance of communication skills, it might not have been enough to completely change participants' workplace behaviours.

I would say it was a very much-needed day because there's been so much change, and it's been an intense environment at [location]... Do I think it's changed anything and will continue to change something? No. I think [location] needs something like that more often than they get because there's still those intense moments and there's still that tension within staff, and the division between part-time and fulltime. I think that's always going to be present at [location]. (Participant 10B)

Therefore, while the workshop did seem to serve as a primer to get participants talking and thinking about this important aspect of professional development, continued development is necessary in order to have a greater impact on communication skills. In fact, during the postworkshop interviews, many participants expressed that that this type of development opportunity needed to occur more often. They suggested that this was necessary not only to ensure sustained development of their professional skills, but also to help sustain cohesion when new staff members come on board and to serve as a way for team members to continue to get to know each other outside of the demands of the social work environment.

I think it would be beneficial if it was more than a one-day workshop. For a one-day workshop, I feel like it was just a fun one-day thing. If it was built into a series, it could definitely build up a stronger team in the workplace. (Participant 8C)

Post-workshop thoughts on using the arts for professional development

Given that the pre-workshop interviews helped to elucidate some of the participants' existing conceptions of using the arts for professional development, we were interested in using the post-workshop interviews to explore whether participants' views had changed regarding this concept. Participants overwhelmingly felt that the workshop had taught them something about using art for professional development. In particular, many participants viewed art with a more 
open mind than they had before, recognizing that it could take many more forms and have more purposes than they had initially thought.

[Before] I just thought of it as drawing, or colouring, or painting. But I see now where it's different ... you can actually use it to talk. (Participant 7A)

Moreover, many of the staff members who had previously seen art as something you had to be talented at in order to engage with were more appreciative of its accessibility to a wider group of participants after completing the workshop.

Before, I used to think that you needed to have a specific talent to do some arts and to participate in arts ... But I realized through this workshop that you can just learn as you go because it's art and you're creating something. You're not going to get it perfect, but you're not going to get it wrong because you're making something that's going to be a piece of art. (Participant 2C)

Notably, several participants mentioned that they found the creative activities during the workshop to be things that they could take back to their workplaces and use with their own clients.

This may be just making me a little bit more mindful about how I can use [art] in a teaching way ... It just reminds me that ... it can be very powerful and maybe even a better teaching method. (Participant 9C)

Therefore, for most participants, the use of the arts to enhance teamwork and communication skills seemed to add value to the workshop and expanded their views on what creative activities may be used for and who can participate in them.

\section{Manager interviews}

We sought to triangulate participants' views of the Centre[3] Professional Development Workshops with that of their managers, who were interviewed one month post-workshop to identify whether or not they had noticed any effects on their team. Once again, the following elements were explored: overall perceptions, specific impacts of the workshop on teamwork and 
communication, and perceptions of the use of the arts for professional development (see

Supplementary Table 3 for a summary of findings from the manager interviews).

Overall perceptions

Much like the front-line staff, the managers had positive perceptions of the workshops.

They believed that the workshops had benefited their teams by providing them with an

opportunity to do something fun together as a team — an opportunity that they did not often have given the nature of their work environment.

The staff loved it. They said that ... they don't really get a lot of opportunities to go out and just be with each other so they loved being out and doing the activities that you had for them. (Manager 3)

Specific impacts: teamwork and communication

When asked if they had noticed any specific changes in their work environment or in their employees following the workshop, two of the managers were able to provide clear examples of positive changes. One manager indicated that she had seen the work environment become more positive, and that the team seemed to have a closer bond than before.

I think it's a lot more positive environment and a positive relationship between the staff ... It's almost like there's inside jokes among them, which is nice to see. (Manager 2)

She also believed that the workshop had made her team more open to sharing ideas during team discussions, a view that was also supported by another manager.

There's been some talk ... among themselves around decision-making a little bit, and a bit about trust, all of which are good things for the team ... they [are] thinking about those in a different way than ... before. (Manager 4)

Manager 4 also shared a story about how during a group meeting, one team member was having difficulty coming up with an idea, and another team member helped encourage them by drawing upon a shared experience from the workshop. 
In one of our team meetings, one of the [staff] was coming up [with] some ideas and they were struggling a little bit, and then I saw someone say, "Remember when we were doing the art project?" and it acted as a trigger to help the person do some of their thinking. (Manager 4)

The same manager had also noticed that staff seemed more willing to come forward with solutions to organizational problems following the workshop.

I have seen a couple people come forward ... sometimes it's [with] concerns but sometimes it's [with] ideas, and it does seem to be looking for change ...Whether it's directly connected to your workshop or not, I would not say a hundred percent, but I would say that it's certainly reinforced that kind of thinking. (Manager 4)

However, the other two managers indicated that while they felt that the workshop was a positive experience for their staff, they had not seen any specific changes in their work environment or in their staff following participation in the workshop. For the most part, they believed that this was because they already had a very cohesive team prior to the workshop.

This is a group that has been working together for many years, average three and a half or more years together, so they are usually pretty relaxed with each other. So, I haven't seen significant changes. (Manager 3)

A second emergent finding was the idea that while this one-off workshop did seem to have a positive impact, managers agreed that sustained development in this regard would be necessary for a longer-lasting impact. Unfortunately, time and cost were cited as major barriers to providing this type of an opportunity on a more regular basis.

If we could [do it more often], that would be great. It comes down to budgets and time. That's always it. (Manager 1)

Thoughts on using the arts for professional development

All four managers had a very positive view on using the arts for professional development, citing many of the same advantages as their staff. For example, Manager 4 talked about the accessibility of art to everyone, not just those who are "good" at it. 
It's not the form; it's the process ... Even someone like me who... doesn't see themselves as creative that way could still use pieces of that to contribute and to build on things to trigger... bigger picture thinking ... or ... maybe coming at things in a way that they might not have originally. (Manager 4)

Managers described how, by working together, the staff members were able to create a piece of shared artwork (a mural) that is now displayed at their workplaces. Two of the managers mentioned this idea of creating something tangible together that can serve as a reminder of the experience as having been a specific benefit of using the arts for professional development.

The picture they came up with that's framed is in our staff room right now. It's in their office and we made a point of making sure it was displayed. (Manager 4)

While some managers indicated that their staff seemed excited about engaging in a creative workshop due to their prior experience with and appreciation for art (e.g., with their clients or through personal hobbies), others said that they were initially a little more apprehensive but then became more comfortable with the idea through encouragement.

When staff initially heard about it, I think they were more apprehensive ... but the more staff get excited about it or the managers encourage [them], I think that helps them get more excited about it. (Manager 2)

\section{Discussion}

This study examined whether creative professional development workshops could facilitate the development of teamwork and communication skills among front-line mental health and social services workers. Our data revealed that the workshops were successful in enhancing teamwork skills among participants and showed promise in the development of communication skills, though not all participants were able to identify tangible changes in their communication skills the way they were able to with regard to their teamwork skills. Interestingly, two of the managers that we interviewed were able to provide specific examples of positive changes with 
respect to both teamwork and communication skills following the workshop. The other two managers did not identify any specific changes, but believed that this was because their teams were already strong in both skills prior to participating in the workshop.

Based on both participants' and managers' reports, professional development that occurred in the context of teamwork centered on helping participants become more comfortable around their colleagues, creating a more enjoyable and relaxed work environment, and encouraging colleagues to be more accepting of one another. The workshops also helped participants identify the strengths and weaknesses of their communication skills, made them more comfortable with various communication styles, and provided them with strategies that could enhance their communication skills. However, continued development, rather than a onetime workshop, is likely necessary in order to observe lasting changes in these skills.

The creative aspects of the workshop, which included various interactive teambuilding activities rooted in the dramatic arts and a printmaking session, were particularly well received by participants who enjoyed the hands-on, interactive nature of the workshop. The workshop experience was successful in helping participants to appreciate the use of the arts for professional development and to be more open-minded to creative experiences. It also benefitted them professionally, given that it provided some strategies that they could use with their own clients.

Our results support the idea that the arts are a useful tool for teaching teamwork and communication skills to healthcare professionals. Perry et al. [1] identify two primary mechanisms by which the arts may confer a benefit in the health professions. First, observing others engaging in art-making or in performance can "directly provide [participants] with a 'simulation' of the wider experience of life necessary for mature interaction with other human beings, which might otherwise be unavailable to them" [p. 142]. For example, watching a theatre 
performance would allow an observer to watch an actor (who, in some cases, may be their colleague) display his or her emotions through both words and body language. This may evoke similar emotions, or at the very least reflection, in the observer.

Second, participants benefit from the arts through direct engagement. In this case, participation in the artistic process can help participants examine, challenge, and sometimes even alter their ways of thinking [1]. This approach is particularly effective because the experiential nature may more easily foster an emotional connection in the participant [1]. As described in a study of pre-service teachers by Ogden [10], participation in a group performance was a new experience for many participants and at times, evoked feelings of vulnerability. Yet, upon reflecting on the experience, participants attributed part of the bonding that took place to having had the opportunity to share emotions and experiences with their colleagues. Thus, in the context of health professionals, novel or unexpected experiences may lead them to experience—and be able to better empathize with - the emotions that their patients or colleagues may be facing. Much like the second (experiential) mechanism proposed by Perry et al. [1], Case and Brauner [11] suggest that one of the roles of art in professional development is to foster an "empathetic imagination," a cognitive skill set that is fundamental to effective interactions with other human beings and is an "inventive process for generating ideas, solving problems, and creating possibilities" [p. 160]. In fact, Case and Brauner view the day-to-day activities of a health professional as a performance in and of itself. They emphasize that this conceptualization is not one that suggests disingenuity, but rather one that implies an "acknowledgement of learned behaviours developed to meet critical objectives" [p. 160]. For example, one can note the many parallels between health professionals and performing artists, including the symbolic costumes (e.g., the white coat of the physician or the loose gown of the patient) and the well-established 
scripts that are learned, and often consciously, rehearsed, prior to the "performance" [11].

Therefore, conceptualizing medical practice as performance in "everyday" situations and spaces such as hospitals and clinics provides one way of understanding how the arts can have a direct role in fostering the development of healthcare professionals, particularly in relation to interpersonal skills. This, in turn, allows for the development of opportunities that allow for more deliberate learning and can help produce individuals who are better equipped to understand and perform their roles as health care providers.

\section{Limitations and directions for future work}

Our work was unique in that it relied upon data from multiple sources in order to examine the efficacy of creative professional development workshops and attempted to more deliberately examine outcomes related to teamwork and communication skill development. In this way, we were able to avoid some of the limitations of other studies, including overreliance on a single source of data and a lack of clear behavioural outcomes. However, our work is still limited in that we did rely on subjective accounts from perspectives and their managers. One of the challenges with the measurement of interpersonal skills such as teamwork and communication is that they are harder to measure objectively than technical skills, for example [1]. Nonetheless, we recommend that future studies work towards measurement approaches that can provide more objective measures of interpersonal skill development and that can be examined in conjunction with qualitative studies such as this one. An example is an approach developed by Eisenberg et

al. [22], who evaluated residents' communication skills following participation in a theatre-based development sessions using an Observed Simulation Communication Education and Evaluation (OSCEE) tool modelled after the Objective Structured Clinical Examination (OSCE) that is traditionally used in medical education. Students were required to enter a room and interact with 
an actor, during which they were evaluated by a faculty observer who was also present in the room. A communication skills checklist developed at Virginia Commonwealth University was used for the evaluation, and included the following domains: 1) beginning effectively, 2) listening actively, 3) planning collaboratively, and 4) achieving closure [23].

In addition, while our study had a high participation rate with only a small number of workshop attendees who did not respond to a request for an interview or withdrew from the study, we acknowledge that our sample may have had a small degree of selection bias in that those most likely to respond would have presumably been individuals with an interest in the arts or in the workshop. Therefore, we may have missed the perspectives of individuals who were not as interested in the workshop or in the use of the arts for professional development. Furthermore, it became clear throughout the interviews that the staff members in this particular organization were generally very open-minded about art because of their role in the social services sector where art is often used for therapeutic purposes; therefore, they may have been more amenable to participating and generally more positive about creativity than other teams of health professionals. Further research to determine whether similar workshops with other teams of health professionals will produce duplicate results, is required to assess the generalizability of these programs. Nonetheless, this study provides valuable insight into the role of the arts for the development of interpersonal skills.

\section{Conclusions}

Our results indicate that participation in the arts can be beneficial for the development of interpersonal skills among health professionals. Shared art-making experiences can foster a better sense of cohesion among colleagues, create a more enjoyable and relaxed work environment, and encourage colleagues to be more accepting of one another. They can also help 
participants identify the strengths and weaknesses of their communication skills, make them more comfortable with different communication styles, and provide them with strategies that can enhance their communication skills. Moreover, after participation in arts-based activities, participants may become open-minded about the use of art for professional development its educational applications. Creative professional development workshops hold promise in enhancing teamwork and communication skills, and, as a part of ongoing professional development, can pose a valuable opportunity for team building and skills development.

\section{Declaration of work performed}

RS conceptualized the study. SM, AA, and RS developed the study protocol and interview questions and sought ethics clearance for this work. JB conceptualized, developed, and ran the Centre[3] creative professional development workshops, with the support and direction of CM. AA, SM, CF, NW, and VM conducted and transcribed the interviews with front-line staff and their managers. CF provided guidance around the qualitative analysis employed in this work. AA, SM, CF, NW, and VM coded all interview transcripts. AA completed the final steps of the phenomenological analysis and produced the initial draft of this manuscript, with assistance from CF. RS oversaw the completion of this work and provided critical edits.

\section{Disclosures}

None of the authors have any conflict of interest or other relevant disclosures.

\section{References}

1 Perry M, Maffulli N, Willson S, et al. The effectiveness of arts-based interventions in medical education: a literature review. Med Educ 2011;45:141-8. doi:10.1111/j.13652923.2010.03848.x 
2 Shapiro J, Rucker L, Beck J. Training the clinical eye and mind: using the arts to develop medical students' observational and pattern recognition skills. Med Educ 2006;40:263-8. doi:10.1111/j.1365-2929.2006.02389.x

3 Bardes CL. Learning to look: developing clinical observational skills at an art museum. Med $E d u c ; 35: 1157-61$.

4 Dolev JC, Friedlaender LK, Braverman IM. Use of fine art to enhance visual diagnostic skills. JAMA 2001;286:1020-1.

5 Naghshineh S, Hafler JP, Miller AR, et al. Formal art observation training improves medical students' visual diagnostic skills. J Gen Intern Med 2008;23:991-7. doi:10.1007/s11606008-0667-0

6 Cox SM, Brett-MacLean P, Courneya CA. "My turbinado sugar": art-making, well-being and professional identity in medical education. Arts Health Published Online First: 15 May 2015. doi:10.1080/17533015.2015.1037318

7 Mercer A, Warson E, Zhao J. Visual journaling: an intervention to influence stress, anxiety and affect levels in medical students. Arts Psychother 2010;37:143-8. doi:10.1016/j.aip.2009.12.003

8 Sheingold B, Warson E, Lunsford B, et al. Using art therapy techniques for team building in distance education Doctor of Nursing practice student cohorts. J Interprofessional Healthc 2014;1(1). http://www.jihonline.org/jih/vol1/iss1/4 (accessed Nov 2015). 
9 Klugman CM, Peel J, Beckmann-Mendez D. Art rounds: Teaching interprofessional students visual thinking strategies at one school. Acad Med 2011;86:1266-71.

doi:10.1097/ACM.0b013e31822c1427

10 Ogden H. Authentic arts-based learning in teacher education: A musical theatre experience. Teaching Educ 2010;21:367-83.

11 Case GA, Brauner DJ. Perspective: the doctor as performer: a proposal for change based on a performance studies paradigm. Acad Med 2010;85:159-63.

doi:10.1097/ACM.0b013e3181c427eb

12 Hilliard RE. The effect of music therapy sessions on compassion fatigue and team building of professional hospice caregivers. Arts Psychother 2006;33:395-401.

doi:10.1016/j.aip.2006.06.002

13 van Westrhenena N, Fritz E. The experiences of professional hospice workers attending creative arts workshops in Gauteng. Health Educ J 2013;72:34-46.

doi:10.1177/0017896911430545

14 Eva KW, Regehr G. "I'll never play professional football" and other fallacies of selfassessment. J Contin Educ Health Prof 2008;28:14-9. doi:10.1002/chp.150

15 Accreditation Council for Graduate Medical Education. Common program requirements. 2007.https://www.acgme.org/acgmeweb/Portals/0/PFAssets/ProgramRequirements/CPRs_07 012015.pdf (accessed Nov 2015). 
16 General Medical Council. Good medical practice. 2013. http://www.gmc uk.org/guidance/good_medical_practice.asp (accessed Nov 2015).

17 Royal College of Physicians and Surgeons of Canada. About CanMEDS. 2015. http://www.royalcollege.ca/portal/page/portal/rc/canmeds/about (accessed Nov 2015).

18 Holzman L, Newman F. The Practice of Method: An Introduction to the Foundations of Social Therapy. New York, NY: New York Institute for Social Therapy and Research 1979.

19 Omery A. Phenomenology: a method for nursing research. ANS Adv Nurs Sci 1983;5:49-63.

20 Giorgi A, Fischer CI, Murray EL. Duquesne Studies in Phenomenological Psychology. Pittsburgh, PA: Dusquesne University Press 1975.

21 Giorgi A, Knowles R, Smith DL. Duquesne Studies in Phenomenological Psychology. Pittsburgh, PA: Dusquesne University Press 1979.

22 Eisenberg A, Rosenthal S, Schlussel YR. Medicine as a performing art: what we can learn about empathic communication from theater arts. Acad Med 2015;90:272-6. doi:10.1097/ACM.0000000000000626

23 Dow AW, Leong D, Anderson A, et al. Using theater to teach clinical empathy: a pilot study. J Gen Intern Med 2007;22:1114-8. doi:10.1007/s11606-007-0224-2 
Supplementary table 1. Pre-workshop interviews: summary of findings

\begin{tabular}{|c|c|c|c|}
\hline Element & Example Quote & Part. & Finding \\
\hline \multirow[t]{3}{*}{$\begin{array}{l}\text { Pre-workshop } \\
\text { perceptions of } \\
\text { teamwork and } \\
\text { communication }\end{array}$} & $\begin{array}{l}\text { "We're a pretty small team at [primary } \\
\text { location], so being such a small number it } \\
\text { just makes it easier to work together and } \\
\text { communicate together." }\end{array}$ & $1 \mathrm{~A}$ & $\begin{array}{l}\text { Two of the four teams reported strong } \\
\text { teamwork and communication skills in } \\
\text { their immediate work environment. These } \\
\text { teams tended to be smaller and more stable } \\
\text { in their membership. }\end{array}$ \\
\hline & $\begin{array}{l}\text { "Well, it's been changing. Things have } \\
\text { been shifting with the team. We've had a } \\
\text { lot of changes in staffing. Some people } \\
\text { have moved on to other organizations; } \\
\text { some people have left [organization } \\
\text { name]. So, yeah it's changing ... a shifting } \\
\text { dynamic." }\end{array}$ & $6 \mathrm{~B}$ & $\begin{array}{l}\text { On the other hand, participants from the } \\
\text { other two primary locations were divided } \\
\text { in their perceptions of teamwork and } \\
\text { communication. This was attributed to } \\
\text { several factors, including a work } \\
\text { environment that had recently undergone a } \\
\text { considerable number of staffing changes. }\end{array}$ \\
\hline & $\begin{array}{l}\text { "We regularly usually have about } 20 \text { to } 22 \\
\text { youth staying at the shelter, so then [there } \\
\text { are] two people that have to pass on } \\
\text { information about } 22 \text { kids that happened } \\
\text { during that eight-hour shift. So, obviously } \\
\text { it's going to be overwhelming and we } \\
\text { could be better at communicating ... } \\
\text { because sometimes [things] fall under the } \\
\text { cracks, right? So, there can be better } \\
\text { communication but I don't know how we } \\
\text { could overcome that. That's just } \\
\text { something that will always be there." }\end{array}$ & $4 \mathrm{C}$ & $\begin{array}{l}\text { Regardless of their overall perceptions, } \\
\text { many participants mentioned that a lack of } \\
\text { face-time between part- and full-time } \\
\text { employees and a busy work environment } \\
\text { with large volumes of information were } \\
\text { barriers to effective teamwork and } \\
\text { communication in their workplace. }\end{array}$ \\
\hline \multirow[t]{2}{*}{$\begin{array}{l}\text { Attitudes and } \\
\text { expectations }\end{array}$} & $\begin{array}{l}\text { "I have never participated in anything like that, so } \\
\text { I really don't know what to expect to what I will } \\
\text { gain out of it but I'm definitely open to it." }\end{array}$ & $1 \mathrm{~A}$ & $\begin{array}{l}\text { Most participants had a positive or neutral } \\
\text { attitude about the workshop. Some were } \\
\text { unsure about what to expect, but still } \\
\text { seemed open-minded about participating. }\end{array}$ \\
\hline & $\begin{array}{l}\text { "It might provide an opportunity for all of us staff } \\
\text { to be together and discuss any concerns that } \\
\text { we're having with each other [or] with another } \\
\text { team, and maybe even build a better team } \\
\text { dynamic for us." }\end{array}$ & $8 \mathrm{D}$ & $\begin{array}{l}\text { Participants believed that the workshop } \\
\text { could help to facilitate the improvement of } \\
\text { teamwork and communication skills. }\end{array}$ \\
\hline \multirow[t]{2}{*}{$\begin{array}{l}\text { Use of the arts for } \\
\text { professional } \\
\text { development }\end{array}$} & $\begin{array}{l}\text { "I've never really thought about it. I don't know. I } \\
\text { think it would be a good tool I guess, but I don't } \\
\text { really have an opinion about it. I haven't heard } \\
\text { too much about it." }\end{array}$ & $1 \mathrm{~B}$ & $\begin{array}{l}\text { Many front-line workers had not } \\
\text { previously considered the use of arts in } \\
\text { professional development. }\end{array}$ \\
\hline & $\begin{array}{l}\text { "It's great because one thing that I find with art is } \\
\text { that no matter what, there's no right way or } \\
\text { wrong way of doing it. It's art, so that's why it's } \\
\text { great. No matter what you do, it's a great piece of } \\
\text { work. Everyone has their own art." }\end{array}$ & $2 \mathrm{C}$ & $\begin{array}{l}\text { Those who had experience with arts } \\
\text { believed the workshop would allow for } \\
\text { improved expression and communication. }\end{array}$ \\
\hline
\end{tabular}


Supplementary table 2. Post-workshop interviews: summary of findings

\begin{tabular}{|c|c|c|c|}
\hline Element & Example Quote & Part. & Finding \\
\hline \multirow[t]{2}{*}{$\begin{array}{l}\text { Overall } \\
\text { perceptions }\end{array}$} & $\begin{array}{l}\text { "It was great. It really exceeded my } \\
\text { expectations. I knew that they were } \\
\text { planning on doing art to build teamwork } \\
\text { and I had a really silly idea of what that } \\
\text { looked like in my head even though I knew } \\
\text { that theoretically it's a good idea. But I } \\
\text { had a really good time." }\end{array}$ & $3 \mathrm{~B}$ & $\begin{array}{l}\text { Participants' perceptions of the workshops } \\
\text { were very positive, and many were } \\
\text { surprised by how much they enjoyed the } \\
\text { experience. }\end{array}$ \\
\hline & $\begin{array}{l}\text { "I honestly think it should be a } \\
\text { continuation. I think it was super } \\
\text { beneficial, especially in this field. We do } \\
\text { need days where we can just work as a } \\
\text { team not at work. Those days are } \\
\text { extremely important." }\end{array}$ & $6 \mathrm{~B}$ & $\begin{array}{l}\text { However, participants felt that these types } \\
\text { of team development opportunities needed } \\
\text { to occur on a more regular basis. }\end{array}$ \\
\hline $\begin{array}{l}\text { Specific impacts: } \\
\text { teamwork }\end{array}$ & $\begin{array}{l}\text { "I find it's now easier to talk with certain } \\
\text { staff members ... where before it was only } \\
\text { about work things. It definitely opened up } \\
\text { for [it]... to be easier to talk to certain } \\
\text { people." }\end{array}$ & $3 \mathrm{C}$ & $\begin{array}{l}\text { With respect to teamwork, the workshop } \\
\text { allowed participants to feel more } \\
\text { comfortable around their colleagues, } \\
\text { created a more enjoyable and relaxed work } \\
\text { environment, and encouraged colleagues } \\
\text { to be more accepting of one another. }\end{array}$ \\
\hline \multirow[t]{2}{*}{$\begin{array}{l}\text { Specific impacts: } \\
\text { communication }\end{array}$} & $\begin{array}{l}\text { "I think the 'yes, and' and the 'yes, but' was also } \\
\text { a really big communication piece ... Sometimes } \\
\text { you do have to say no to people and you can say, } \\
\text { 'yes, but.' And then sometimes you're trying to } \\
\text { build ideas into work together and then you say } \\
\text { 'yes, and.' I think that that was honestly one of the } \\
\text { best activities." }\end{array}$ & $6 \mathrm{~B}$ & $\begin{array}{l}\text { With respect to communication, the } \\
\text { workshop allowed participants to identify } \\
\text { strengths and weaknesses of their } \\
\text { communication skills, made them more } \\
\text { comfortable with various communication } \\
\text { styles, and provided them with strategies } \\
\text { that could enhance their communication } \\
\text { skills. }\end{array}$ \\
\hline & $\begin{array}{l}\text { "I wouldn't say improvement yet, because it does } \\
\text { take time for all of us... I haven't noticed anything } \\
\text { change yet." }\end{array}$ & $3 \mathrm{D}$ & $\begin{array}{l}\text { However, unlike teamwork, a number of } \\
\text { participants found it difficult to identify } \\
\text { tangible changes in their communication } \\
\text { skills. }\end{array}$ \\
\hline \multirow[t]{2}{*}{$\begin{array}{l}\text { Use of the arts for } \\
\text { professional } \\
\text { development }\end{array}$} & $\begin{array}{l}\text { "I think it's definitely made me more curious of } \\
\text { different types of art. I had never ever done print } \\
\text { work before, so it was really cool to learn about } \\
\text { that process and to get creative within myself." }\end{array}$ & $6 \mathrm{~B}$ & $\begin{array}{l}\text { The workshop experience was successful } \\
\text { in helping participants to appreciate the } \\
\text { use of the arts for professional } \\
\text { development and to be more open-minded } \\
\text { to creative experiences. }\end{array}$ \\
\hline & $\begin{array}{l}\text { "But even the population I work with, we } \\
\text { see that art is really helpful for the kids, } \\
\text { so [during] a lot of the [activities], we } \\
\text { were like, 'Oh, we should go do this with } \\
\text { the kids! We should do this with the kids!" }\end{array}$ & 9B & $\begin{array}{l}\text { It also benefitted them professionally, } \\
\text { given that it provided some strategies that } \\
\text { they could use with their own clients. }\end{array}$ \\
\hline
\end{tabular}


Supplementary table 3. Manager interviews: summary of findings

\begin{tabular}{|c|c|c|c|}
\hline Element & Example Quote & Part. & Finding \\
\hline $\begin{array}{l}\text { Overall } \\
\text { perceptions }\end{array}$ & $\begin{array}{l}\text { "I was at one of my community meetings } \\
\text { and the issue around staff morale came } \\
\text { up... I actually gave you a little plug in } \\
\text { that I thought that it had been beneficial } \\
\text { for our team." }\end{array}$ & M4 & $\begin{array}{l}\text { Like their employees, the managers also } \\
\text { had very positive views of the workshop } \\
\text { and were happy to recommend it to others. }\end{array}$ \\
\hline \multirow[t]{3}{*}{$\begin{array}{l}\text { Specific impacts: } \\
\text { teamwork and } \\
\text { communication }\end{array}$} & $\begin{array}{l}\text { "They discuss more. I don't know if I see a change } \\
\text { in the way they present their ideas, but ... in team } \\
\text { meetings or in brainstorming sessions, [we have] } \\
\text { more ideas flow [ing]." }\end{array}$ & M2 & $\begin{array}{l}\text { Two of the managers were able to provide } \\
\text { specific examples of how the workshop } \\
\text { had benefitted their team's teamwork and } \\
\text { communication skills. }\end{array}$ \\
\hline & $\begin{array}{l}\text { "We've always been a team that does a lot } \\
\text { of problem solving together, so it's always } \\
\text { been open communication. So, I haven't } \\
\text { seen any significant change, no." }\end{array}$ & M1 & $\begin{array}{l}\text { The other two managers indicated that } \\
\text { they had not seen any tangible changes in } \\
\text { teamwork and communication skills, but } \\
\text { believed that this may have been because } \\
\text { their team was already strong in these } \\
\text { areas to begin with. }\end{array}$ \\
\hline & $\begin{array}{l}\text { "What [the staff] had asked is that we do } \\
\text { it more often, that we afford them the } \\
\text { opportunity of going and doing it... So, } \\
\text { money-wise, I don't know if we would be } \\
\text { able to afford it, but as a management } \\
\text { team, we need to discuss ways to make it } \\
\text { more available to staff. Days where, you } \\
\text { know, they can go out and not have us } \\
\text { around and strategize how they are going } \\
\text { to communicate." }\end{array}$ & M3 & $\begin{array}{l}\text { Managers supported their colleagues in } \\
\text { their idea that the workshops become a } \\
\text { more regular occurrence, but perceived a } \\
\text { lack of resources (i.e., time and money) to } \\
\text { be a barrier. }\end{array}$ \\
\hline $\begin{array}{l}\text { Use of the arts for } \\
\text { professional } \\
\text { development }\end{array}$ & $\begin{array}{l}\text { "Without creating tensions or any kind of } \\
\text { situation where they were uncomfortable, } \\
\text { [the workshop] really created an } \\
\text { environment where [the staff] could feel } \\
\text { welcome and put their ideas forward." }\end{array}$ & M3 & $\begin{array}{l}\text { Managers had a very positive view about } \\
\text { using the arts for professional } \\
\text { development. In particular, they felt that } \\
\text { art could create an inclusive environment } \\
\text { that fosters expression and the sharing of } \\
\text { ideas. }\end{array}$ \\
\hline
\end{tabular}

